\title{
El caso de la mafia italiana en los tipos de terrorismo gubernamental* The Case of the Italian Mafia in the Types of State Terrorism
}

\author{
Victoriano Perruca Albadalejo \\ Universidad Nacional de Educación a Distancia \\ vperalb@mde.es
}

Recibido / received: 26/07/2018

Aceptado / accepted: 01/03/2019

DOI: https://doi.org/10.20318/eunomia.2019.4691

\begin{abstract}
Resumen
En este trabajo exponemos la definición y tipos de terrorismo de Estado para relacionar el caso ya judicializado de la mafia italiana dentro del contexto pernicioso del crimen internacional $y$, aparte de otras conclusiones, cuál sería su encuadre con arreglo a aquella clasificación doctrinal y estándar.
\end{abstract}

\section{Palabras clave}

Terrorismo de Estado, mafia italiana, crimen internacional.

\begin{abstract}
In this job we are trying to Know what is the definition of governmental terrorism and his several kinds in order to making the Italian mafia up when it was trialed just in a context of international crime and according to general opinion some experts.
\end{abstract}

\section{Keywords}

Governmental terrorism, Italian mafia, international crime.

\footnotetext{
* Diversas partes del presente trabajo se recogen de modo más extenso en el texto de mi tesis doctoral inédita "La actuación de las fuerzas armadas en situaciones de guerra y terrorismo según su conexión fenomenólógica e histórico-jurídica", disponible en: http://e-spacio.uned.es/fez/eserv/tesisuned:DerechoVperruca/PERRUCA ALBADALEJO Victoriano Tesis.pdf
} 
SUMARIO. 1. Definición de terrorismo de Estado. 2. Tipos y ejemplos. 2.1. El de los Estados totalitarios donde "la aniquilación del enemigo" está más o menos formalizada en su Legislación. 2.2. El de las extralimitaciones de los poderes públicos en la lucha contra el terrorismo. 2.3. El de la violencia ejercida por grupos "paramilitares" o por los propios cuerpos de seguridad, pero al margen de la Ley, aunque con una absoluta o imparcial impunidad. 3. El caso de la mafia italiana. 3.1. Origen geográfico. 3.2. Concepto y diferencia con el terrorismo. 3.3. Su giro terrorista: el caso Andreotti. 3.4. Organizaciones mafiosas italianas. 3.5. Juicio del siglo. 3.6. Su perversidad y remedio. 4. Conclusiones. Bibliografía.

\section{Definición de terrorismo de Estado}

Fue Quintano Ripollés en los años cincuenta del siglo pasado quien en palabras que han quedado inmortalizadas en resolución judicial definió y trató del "terrorismo de Estado" -a diferencia del terrorismo subversivo- como "una forma de terrorismo que parece haber tenido una lamentable tendencia a proliferar en nuestro tiempo, tan propicio a todos los monopolios estatales, es el del "terrorismo de arriba"; esto es, el practicado por el Estado abierta o encubiertamente a través de sus órganos oficiales u oficiosos, es claro que desborda obviamente el campo propio del Derecho Penal Interno, aunque pueda importar al Internacional Penal en la dimensión de los llamados Crímenes contra la Humanidad o los Genocidas. Es, sin duda, el aspecto más vil del terrorismo, dado que elimina todo riesgo y se prevale del aparato de la autoridad para perpetrar crímenes bajo el ropaje de la autoridad y aun del patriotismo"1.

Por su parte, a pesar de que se desconoce su origen y la procedencia etimológica de su nombre (Dáll'Anese, 2012) ${ }^{2}$, cuando hablamos de "Mafia" nos referimos a "una forma de poder criminal que reproduce o remeda elementos del poder estatal y trata de recibir compensaciones que pueden considerarse análogas a las que, normalmente, están reservadas al Estado" (Linde, 2006). Es un poder que no tiene otro objeto que el reforzamiento de su propia capacidad de dominación. Éste es un rasgo esencial de lo que los expertos en ciencia política denominan "Estado depredador", esto es, aquel que se distingue de otro "contractual" en el hecho de que "los gobernantes depredadores, aunque pueden proporcionar a sus clientes o vasallos bienes públicos, como orden y protección contra el crimen perpetrado por otros, no tienen como objetivo, ni siquiera, diríamos, fingido, el bienestar de sus clientes, sino la maximización de su riqueza y de su capacidad de dominación; en realidad, un Estado depredador es algo muy cercano a una situación en la que un territorio y una población determinados están sometidos a un bandido hegemónico, un bandido monopolista" (Moselle y Polak, 2001: 28-29).

\section{Tipos y ejemplos de terrorismo de Estado}

En la actualidad no es inimaginable que la Organización terrorista esté constituida por un Gobierno determinado y en este sentido, siguiendo a González Cussac (2006: 7576), distingue tres casos:

\footnotetext{
${ }^{1} \mathrm{FJ} 6^{\circ}$ del Auto del Pleno de la Sala de lo Penal de la Audiencia Nacional, de 4 de Noviembre de 1998.

2 Por su parte, se afirma que "[...] el uso estricto y más apropiado del término debería circunscribirse a la Cosa Nostra" (Dovizio, 2005: 95, nota 1).
} 
2.1. El de los Estados totalitarios donde "la aniquilación del enemigo" está más o menos formalizada en su Legislación.

El caso de la Alemania nazi o la limpieza étnica realizada en 1994 en Ruanda, entre otros $^{3}$, son claros ejemplos de "genocidio". El de las dictaduras chilena y argentina ${ }^{4}$ lo son de "crímenes de lesa humanidad".

Ambos no constituyen delito de "terrorismo propiamente" dicho desde el punto de vista jurídico aunque sí se puedan ejecutar con actos no menos graves de terror.

Para la STS 1.10.07 (ponente Colmenero Menéndez de Luarca) "la diferencia esencial entre los crímenes contra la Humanidad y el delito de genocidio es la limitación de los grupos perseguidos y especialmente la exigencia de la intención o propósito de destruir al grupo parcial o totalmente, que es elemento del segundo de ellos".

La diferencia con respecto al terrorismo es que tanto el de lesa humanidad como en el de genocidio hay un elemento común de "prevalimiento de poder". Por tanto, cuantitativa y cualitativamente se trata de delitos todos ellos distintos.

En el comentario de la Operación Cóndor ${ }^{5}$ afirmamos que fue un terrorismo de Estado puro y duro. Se manifestó en Argentina en que -a través del golpe de estado de una Junta Militar- se utilizaron a las Fuerzas Armadas para llevar a cabo la apropiación del Estado con el fin realizar a la vez también un exterminio planificado. Hubo detenciones y asesinatos masivos que no eran ejecuciones oficiales por realizarse de forma clandestina. En primer lugar (secuestro) se les secuestraba, normalmente de noche, en sus domicilios. Eran operaciones que a menudo incluían el saqueo y robo de la vivienda. En segundo lugar (tortura) se les torturaba y sólo si lo superaban, porque muchos se "quedaban", permanecían detenidos en dependencias policiales y unidades militares. A la mayoría de ellos les aguardaba, por último, el "traslado", la ejecución sin dejar prueba alguna. Hubo vuelos en que los

\footnotetext{
3 También se puede mencionar el estalinismo con su terror planificado de los años treinta, la campaña militar bestial de Japón en Manchuria en 1931-1933, la gran "Revolución cultural" maoísta, la dictadura del Benefactor Trujillo en la República Dominicana durante los años cuarenta y cincuenta, el régimen de terror del líder "marxista-lenislista" de Etiopía, entre 1974 y 1991, Haile Mariam Mengistu, o el régimen gangsteril de Robert Mugabe en Zimbaue, así como la explosión genocida de tiranías como la del PolPot con el régimen de los Jemeres Rojos en Camboya.

${ }^{4}$ El caso de la Operación Cóndor y los vuelos de la muerte.

5 Puede verse al respecto el periódico El País del miércoles 6 de marzo de 2013, Sección Internacional, página 14, con el título de "Juicio al horror sudamericano", donde se dice que la causa se inició en los noventa, cuando regían las amnistías en Argentina, pues los casos del Plan Cóndor habían quedado excluidos de ellas. En esos años fallecieron varios responsables de la operación. En otros países, como Chile y Uruguay, la justicia también ha investigado a los responsables del Cóndor, pero en este último país toda indagación sobre los crímenes de la dictadura quedó paralizada en febrero de 2013 por una resolución de la Corte Suprema de ese país. Mientras tanto, en Brasil sólo se indaga dentro de la Comisión de la verdad creada por la presidenta Dilma Rousseff, y en otra subcomisión legislativa sobre el mismo asunto. De momento, sólo cuatro crímenes del Cóndor han sido juzgados. Según La Gaceta de 26.07.13, p. 29.: "Un militar de Kirchner, a juicio", incluso sobre el jefe del Ejército en la actualidad, César Milani, pesa la sospecha de haber participado en actos ilegales de represión política en tiempos de la dictadura militar, el llamado "proceso de reorganización nacional". Concretamente su nombre aparece vinculado a torturas e interrogatorios sobre presuntos miembros del Ejército Revolucionario del Pueblo, hechos que se remontan a 1976. En Argentina, desde hace años, todos los nombramientos militares y civiles han de pasar oficiosamente por el cedazo del denominado Centro de Estudios Legales y Sociales (CELS), que dirige el periodista Horacio Verbitsky, cuyo fin expreso es depurar la Administración. De momento, la aprobación del ascenso de Milani ha quedado suspendida hasta diciembre del 2013. En 2012, según información de El País del sábado 18 de Mayo del 2013, en la sección de Internacional (la muerte de un dictador), con el artículo de Francisco Peregil: "Jorge Rafael Videla, punto final", el número de condenados sumaban ya 244.
} 
detenidos eran arrojados al río de la Plata o a la mar desnudos, atados de pies y manos gracias a que la Escuela Mecánica de la Armada (ESMA) era el mayor centro de tortura y exterminio del país. "Desaparecido" fue el eufemismo con el que se denominó a las víctimas de esa dictadura. El ex dictador Videla, antes de morir en Mayo de 2013, sería condenado a prisión perpetua un año antes por organizar el Plan sistemático de desaparición incluso de bebés detenidos, así como de los asesinatos y robos de unos cuatrocientos hijos de embarazadas cautivas, es decir, de desapariciones por las que tales madres daban en silencio y protesta vueltas por la Plaza de mayo.

El camino, pues, que se ha seguido para el enjuiciamiento ha sido largo. En Diciembre de 1986 el Congreso argentino aprobó la Ley 23.492, conocida como "Punto Final", que dio un plazo de dos meses para denunciar a represores. En Junio del año siguiente se aprobaría la Ley de Obediencia Debida, según la cual los oficiales de rango inferior y los suboficiales actuaron forzados por los mandos superiores. En Octubre de 1989 el Presidente Menem indultaría a doscientas setenta y siete personas, incluidos acusados de crímenes de lesa humanidad, significando que al año siguiente el propio Videla, así como Viola, su sucesor, se beneficiarían de otro indulto el año posterior, hasta que en realidad en Marzo de 1998 el Parlamento argentino derogaría las leyes anteriores de punto final y obediencia debida, sin efecto retroactivo, si bien en Junio del año 2005 la Corte Suprema declaró inconstitucionales las citadas normas. Cabe decir que tras el indulto de 1990 referido entró en juego España y el principio de la jurisdicción universal recogido en nuestra normativa, es decir, el principio que le valió al Juez Baltasar Garzón para imputar a Videla por entender que en todo caso las leyes de amnistía, olvido o punto final no son aplicables a los crímenes de lesa humanidad, si bien es cierto que la condena de Videla podría decirse que empezó, en realidad, con Fujimori, el Presidente de Peruano de origen nipón. Tras plantearse la inconstitucionalidad de las leyes de Obediencia Debida y de Punto Final argentinas a raíz de una Sentencia de la Corte Interamericana de Derechos Humanos, que anuló en 2001 la auto-amnistía de Alberto Fujimori en Perú, ese caso se sumó al desarrollo del Derecho Penal Internacional y la constitución de los Tribunales especiales de la Ex Yugoslavia y Ruanda, que avanzaron en los principios de que en los casos de lesa humanidad los Estados tienen obligación de castigar a los responsables.

En estos casos citados, pues, hay un Estado totalitario, pero también cabe que un Estado democrático se extralimite en la lucha contra el terrorismo.

Fue el caso, por ejemplo, de la guerra sucia que el régimen de De Gaulle emprendió contra el movimiento independentista argelino antes de verse forzado a conceder la independencia de la ex colonia: Paul Aussaresses ${ }^{6}$, bajo las órdenes del General Jacques Massu e integrado en la décima división de paracaidistas que dicho

\footnotetext{
${ }^{6}$ Puede verse al respecto el artículo "la guerra de Argelia en el Glosario de la Historia de las Relaciones internacionales durante el siglo XX", de la Revista Historias siglo20.org, en el apartado de Guerra Fría. Página web: www.historiasiglo20.org/GLOS/guerraargelia.htm. Vid. también El Mundo de 12 de Diciembre de 2013, p. 20, Sección "Obituarios". Tras numerosos atentados perpetrados por los independentistas, el gobernador civil de la colonia decidió delegar todos los poderes en Massu, quien instauró la Ley Marcial y confió a Aussaresses el mando de "la guerra sucia" (detenciones ilegales, torturas, ejecuciones arbitrarias, desaparecidos,...). Más que un soldado de primera línea de combate, fue un experto de la lucha encubierta y un eficaz represor, cuyos métodos enseñó durante los años sesenta en los EE.UU aleccionando a los boinas verdes sobre técnicas de contra-insurrección que más tarde aplicarían en Vietnam. En plena dictadura brasileña de Emilio Garrastazu este maestro de la represión fue nombrado profesor en el Centro de Formación de la guerra en la Selva de Manaos y allí tuvo, entre otros alumnos, a numerosos miembros de la policía Política del tirano Pinochet.
} 
General mandaba, se encargó de reprimir brutalmente las actividades de terroristas del Frente de Liberación Nacional argelino en la Batalla de Argel.

Otro caso más moderno es el de la neonazi Nschäpe ${ }^{7}$ (cómplice en los asesinatos y en la preparación de los explosivos que, en 2004, dejaron estupefacta a la sociedad teutona por el terror causado en un barrio habitado por inmigrantes en Colonia).

Por último, comentaremos posteriormente el caso de la Mafia italiana como forma de presión a un Estado democrático para que éste se involucre en el crimen internacional y que, a tenor de lo mantenido con anterioridad, sobre todo con la diferencia entre un Estado depredador y otro contractual, puede considerarse como una forma de terrorismo estatal.

\subsection{El de las extralimitaciones de los poderes públicos en la lucha contra el} terrorismo.

Hay más casos parecidos al anterior ya cometidos por las fuerzas propias de seguridad y no las de estrictamente militar, incluso a veces en el propio territorio estatal.

El caso de Grupos Antiterroristas de Liberación, como el de Israel contra la Organización palestina Septiembre Negro creado tras los famosos atentados de las Olimpiadas de Münich (1972) o el del GAL (SAN 20.09.01 -Ponente Lobejón Martínezy STS 20.07.01 -Ponente Giménez García-) en España, es el "terrorismo de Estado" (o de arriba) de los que más rechazo ha provocado dentro y fuera de nuestras fronteras, significándose que la estructura penal para su castigo es cualitativamente distinta de la del terrorismo "subversivo" (o de abajo): mientras este último ataca los mecanismos de una toma "legítima" de decisiones de un Estado, que pensamos ${ }^{8}$ que no tiene por qué ser sólo el "democrático", por su parte el terrorismo de Estado no

\footnotetext{
${ }^{7}$ Lo peculiar del caso es que entre el año 2000 y el 2007 ni la policía ni los servicios secretos, ni tampoco la prensa, dieron con la pista neonazi. Las autoridades insistían en que se trataba de crímenes mafiosos. Eso permitió que si diversas bandas terroristas se habían ocultado en el pasado en santuarios extranjeros, selvas tropicales o cuevas remotas, por el contrario este trío neonazi vivió y mató en pleno corazón urbano, regulado y limpio de Europa, y a pesar de que se sabe que en Alemania hasta se toma datos de los ciclistas que no usan luces nocturnas. Incluso los terroristas tenían tal sensación de impunidad que Beata Zschäpe se dejó grabar por una cámara de la televisión pública cuando hacía gimnasia junto a un cámping donde en 2011 disfrutaba de unas vacaciones con sus cómplices y tras más de diez años asesinando gente. El propio jefe de la Comisión de investigación que lleva el caso en el Bundestag ha llegado a reconocer que hasta los propios espías alemanes han entorpecido el esclarecimiento de los hechos y que, junto con el escándalo de la destrucción de expedientes sobre los neonazis del Este por algunas oficinas regionales de los servicios secretos, se está ante el peor fracaso masivo e inaudito desde la fundación de la República Federal Alemana.

Tampoco España se escapa de la existencia de bandas nazis. En Cataluña, por ejemplo, se sabe de la banda nazi de "skin heads White Rebels Barcelona" (WRB), a cuyo líder se le pidió por el fiscal catorce años de cárcel por la paliza que en el día 7 de abril del 2011 se le propinó en un Bar de Barcelona, acorralándolo y agrediéndole en la cabeza con cadenas de hierro y botellas, a un ex miembro del grupo que había empezado a relacionarse con personas de ideología contraria, sobre todo aquellos sobre los que se practicaba cierta cacería y que eran inmigrantes y homosexuales. Acusado el dirigente de la organización por los delitos de asociación ilícita en calidad de dirigente y contra los derechos fundamentales y las libertades públicas, en su modalidad de provocación a la discriminación, al odio y a la violencia, el principal colaborador del líder era quien administraba la web de la banda criminal. Vid. El País del martes 30 de Abril del 2013, Cataluña, p. 3, columna derecha: "La Fiscalía pide hasta 14 años a una banda nazi por apalear a un desertor".

${ }^{8}$ A diferencia de Llobet Anglí (2010: 115). Asimismo, y a mayor abundamiento, si el atacado fuera no un Estado sino una organización estatal no democrática, así la ONU, donde no todos sus miembros son democráticos (China, por ejemplo), ni lo es su régimen como tal (derecho de veto por los miembros permanentes del Consejo de Seguridad), no por ello dejaríamos de calificarlo como terrorismo (a diferencia de Llobet, quien lo calificaría (Ibidem: 21-122) como un crimen de lesa humanidad).
} 
respeta los mecanismos de ejecución "legítimos" del ius puniendi, es decir, se toma la justicia por la propia mano (lo primero sustituye al poder constituyente y legislativo, lo segundo, al poder judicial)., Si la corrupción en tal sentido lo fuera a gran escala tales acciones, de lege lata, debieran subsumirse en los delitos de lesa humanidad, siempre que concurran los requisitos de ataque sistemático o generalizado contra la población, apreciándose, además, y en su caso, la agravante de "prevalimiento del carácter público" del sujeto activo; y, caso de no darse aquellos requisitos, en el delito común correspondiente también con dicha agravante.

Casos más modernos que podrían encajar en este tipo estarían, en primer lugar, el caso de Ríos Montt en Guatemala9.

José Efraín Ríos Montt fue el hombre que gobernó este país centroamericano con mano de hierro entre el 23 de Marzo de 1982 y el 9 de agosto de 1983 "quinquenio negro"-. Las guerrillas guatemaltecas asumieron la estrategia que habían seguido las fuerzas de Ho Chi Minh en Vietnam, esto es, la ocupación de poblaciones aisladas y el adoctrinamiento de los jóvenes para la formación de nuevos cuadros guerrilleros. El Estado tenía entonces poca presencia en el llamado "triángulo ixil", y la labor de la captación de las guerrillas contó con poca oposición. En el conflicto guatemalteco -donde también se combatía con las Patrullas de Autodefensa Civil (armadas por el Ejército) a las guerrillas de inspiración marxista- se estima que murieron entre ciento cincuenta mil y doscientas mil personas, siendo el ochenta y tres por ciento de sus víctimas indígenas que no murieron en combate.

En segundo lugar, aunque podría ser discutible su inclusión en esta clase de terrorismo de Estado, probablemente por no caber comparación con el supuesto

\footnotetext{
9 Testimonios en el juicio han llegado a contar cómo los soldados jugaron al fútbol con la cabeza de una anciana, la violación de una indígena embarazada de ocho meses vestida con su colorido güipil, teniendo quince días después un parto con el hijo muerto, lo que da muestras de que según el fallo aún no firme las mujeres y los bebés fueron el centro de la mayoría de las atrocidades cometidas por el ejército. Todo esto hace que los países vecinos también "miren de reojo" una Sentencia que abre la caja de la memoria histórica en una región asolada durante décadas por guerras cocinadas con ingredientes similares. El Tribunal Constitucional de Guatemala ordenó en Mayo de 2013 repetir el juicio a partir del estado en que se encontraba el proceso el día 19 de abril, cuando la vista fue suspendida, reanudándose después sin tener en cuenta testigos propuestos por la defensa del ex dictador. El propio Tribunal que condenó a Ríos deberá poner en marcha la "máquina del tiempo" y dar trámite a la recusación planteada por su defensa contra la juez Yazmín Barrios, por "enemistad grave", a la vez que por "amistad" con otro miembro del Tribunal, Pablo Xitumul. Aunque la Sentencia fue anulada por motivos formales de falta de garantías procesales debidas, la Corte Constitucional no ha puesto en duda las conclusiones sobre los hechos de quince operaciones de matanzas llevadas a cabo contra los mayas ixiles durante la Presidencia de Ríos Mont y en el contexto de un conflicto que asoló el país durante treinta y seis años (1960-1996, fecha esta última de la firma de los acuerdos de Paz).

Sigue pareciendo hoy el caso más atroz de "apartheid" que, aparte de Sudáfrica, pueda haberse conocido. La diferencia con el apartheid sudafricano era que la discriminación racial no estaba escrita en las leyes, de forma que un negro sudafricano era un ser más libre que un indígena guatemalteco. El asesinato era el primer recurso contra los subversivos en Guatemala, en Sudáfrica era el último. Lo mismo no se podía decir de El Salvador, país vecino donde también los militares "disparaban primero y preguntaban después", pero donde el grado de terror, de esclavitud mental, era menor: los campesinos en la zona de guerra salvadoreña se atrevían a hablar con cierta libertad, incluso los soldados pertenecían al grupo de fuerzas especiales más represoras (los llamados Kaibiles), que siendo soldados indígenas en el proceso de entrenamiento militar los había deliberadamente desalmados. Eran víctimas por los oficiales de un método especialmente eficaz para eliminar todo vestigio de compasión en sus corazones. Ese método consistía en que cuando los reclutaban les regalaban un cachorro. Durante medio año en que los transformaban en Kaibiles el único consuelo que tenían los jóvenes reclutas eran sus fieles perros. Al final de ese tiempo los oficiales les obligaban a degollarlos con el fin de convertirlos en "máquinas de matar con cero humanidad" sin necesidad de tener que entender, a diferencia de los funcionarios (así sobre todo los de la CíA que trabajaban en la embajada estadounidense), por qué se luchaba ni se masacraba. Vid. Caso de John Carlin, El País del domingo 12 de Mayo de 2013, p. 12 (Sección Internacional), según su artículo "El Apartheid más atroz".
} 
anterior, al menos por no olvidarlo sí cabe citar el Caso Faisán ${ }^{10}$ en España. Se trató de un presunto "chivatazo" policial por las detenciones que en 2006 se pretendían llevar a cabo de miembros de ETA y su aparato de extorsión, cuyo presunto responsable era el dueño del bar Faisán, Joseba Elosua, frustrando así dicha operación.

\subsection{El de la violencia ejercida por grupos "paramilitares" o por los propios cuerpos} de seguridad, pero al margen de la Ley, aunque con una absoluta o imparcial impunidad.

Por último, cabe otro supuesto doble de su igual manifestación, según sea decisoria o coadyuvante, y que de por sí tiene un elemento internacional: el de que un Gobierno de un Estado no ya constituya el propio grupo armado (Hamás en Palestina cuando ganó las elecciones en 2006) para coaccionar a los dirigentes de otros países mediante la violencia dirigida contra su población, siendo "Estados terroristas" propiamente dichos como tales, sino que preste algún tipo de asistencia material y/o logística a grupos armados ya existentes (en otro país) por razones de afinidad ideológica o mera oportunidad geopolítica (EE.UU en su día a la contra nicaragüense, Afganistán a Al Qaeda, Libia en el caso Lockerbie de 1988, etc.) y que, en el ámbito internacional, donde tiene mayor explicitud, se conoce como el de los "Estados sponsor".

Casos más modernos que también cabrían en esta clasificación podríamos mencionar el caso de las tribus urbanas de "los maras" y los "latin King" (organizaciones surgidas en El Salvador y Honduras dedicadas a dar seguridad en sus barrios al mismo tiempo que no han dejado de ocuparse también del control de las rutas del narcotráfico de su país, es decir, llegándose a especializar en narcotráfico, secuestro, sicariato y extorsiones) ${ }^{11}$ o los caballeros templarios desde Febrero del 2012 en Tierra caliente de Michoacán -México- (y que, ante la falta de una contestación estatal, ha obligado a su vez a la creación de los llamados "grupos

\footnotetext{
10 Se trataba de una operación que podía haber sido crucial para la victoria policial y del Estado de Derecho en esa lucha contra ETA. El grupo terrorista, según investigaciones periodísticas, no sólo recibió el dinero de la extorsión sino que los miembros de la red de chantaje y de extorsión pudieron evadirse antes de ser capturados llevándose consigo pruebas, listas, sellos, datos esenciales sobre la estructura, composición, procedimientos operativos y responsables del aparato financiero de ETA en esos momentos, y otros documentos, así como los nombres de víctimas y de verdugos por culpa, parece ser, y en definitiva, más que probablemente de la posible orden dada por algún responsable político. Aunque las pesquisas sobre este caso empezaron en 2006 al comisario Enrique Pamiés y el inspector José María Ballesteros la Sección Tercera de la Sala de lo Penal de la Audiencia Nacional los ha condenado en Octubre del 2013 a un año y medio de cárcel y cuatro años de inhabilitación por un delito de "revelación de secretos", pero el Tribunal les absuelve del delito de "colaboración con organización terrorista".

Véase el diario El Mundo de 16 de Enero de 2013, p. 14, Sección España, la información subtitulada "La Audiencia avala los procesamientos del Faisán" y según la cual la Sala de lo Penal de dicha Audiencia el día anterior confirmó el procesamiento del ex jefe superior de Policía del País Vasco (E. Pamiés) y del inspector jefe (José M ${ }^{a}$ Ballesteros) como presuntos autores del "soplo" a la trama de extorsión etarra. También el ABC de jueves 27 de Junio del 2013, Sección España, página 29, donde se dice que el juicio está previsto para los días 16 a 18 de septiembre del 2013. En el auto de procesamiento el juez instructor, Pablo Ruz, consideró que había "motivos bastantes" para imputarles los delitos de colaboración con banda armada y revelación de secretos. Sin embargo, indicó que no había indicios suficientes para procesar al entonces Director General de la Policía, Víctor García Hidalgo. Si ambos policías cometieron un delito de colaboración ha generado un intenso debate en el seno del Ministerio Público, puesto que el fiscal jefe de la Audiencia Nacional, Javier Zaragoza, cree que no y el Fiscal General del Estado, Torres Dulce, considera que sí. Por eso, en el escrito de acusación el fiscal del caso hizo constar que incluía ése delito por "orden expresa" de su superior jerárquico.

Véase el diario El Mundo del 24 de Abril de 2013, p. 4, en la Sección España sobre el nuevo escenario vasco, la investigación, con la información titulada "El recibí del chivatazo a ETA".

11 Vid. Botello y Moya (2005), Cerbino (2004) y el artículo "El fenómeno pandillero" de la revista El Monitor, núm. 11 de Noviembre de 2005. Boletín de Vigilancia Tecnológica. Recuperado de: www.uned.es/dpto pen/delincuencia-juv/.../fenomeno pandillero.pdf.
} 
de autodefensa" 12 , es decir, unos grupos de reacción armada compuestos por la propia población afectada).

Respecto a la pregunta que cualquier jurista puede hacerse sobre si a estas bandas criminales se les podría aplicar un proceso de paz de corte político hay que tener en cuenta que, en primer lugar, también es cierto que en Honduras -desde la "ley antimaras de 2002"- pertenecer a ellas y llevar un tatuaje de una de las pandillas ya es un delito de por sí, que para hablar de tal clase de proceso el acuerdo debe de ser entre al menos una de esas pandillas y el Gobierno, pero no un acuerdo entre pandillas (lo que no implica que un acuerdo pueda preceder en su caso al otro), que se trata de un diálogo con organizaciones criminales, que para la rapidez o no de los acuerdos pueden influir variables como las cercanías de unos comicios electorales, $\mathrm{y}$, sobre todo, que las autoridades gubernamentales deben actuar para ello de forma pública, abierta, transparente y legítima o autorizada por el propio Estado.

En caso contrario, aunque se consiga cualquier logro de interrupción de la violencia por tales pandillas, la frustración social sería tan grande como no menos perjudicial para la sociedad del país en general si aquél se viniera abajo por la falta de un requisito jurídico necesario, es decir, porque de repente un Tribunal considerase que quienes llevasen el acuerdo no estuvieran legitimados. Por ejemplo, esto es lo que se teme que pueda ocurrir en Honduras teniendo en cuenta que en este país ya en el año 2006 se intentó una tregua de los maras con el Estado y fracasó. Esa primera intentona de tregua finalmente fracasada tuvo lugar después de que en el Centro Penal de San Pedro Sula, al norte de Tegucigalpa, un infierno cargado de violencia donde los reclusos vivían hacinados en celdas claustrofóbicas y en condiciones de insalubridad, sufriera en el año 2004 un grave incendio que se saldó con un centenar de reos muertos. Sin embargo, aunque ya entonces esas pandillas pidieron perdón ante la sociedad hondureña, en la actualidad existe un proceso de diálogo monitorizado por la intermediación de la Iglesia (el obispo Rómulo Emiliani) y la Organización de Estados Americanos (OEA). Sin embargo, la incertidumbre sobre él no está descartada si se tiene como referencia que en EI Salvador la tregua que fue difundida ya un año y dos meses antes, en Marzo del 2012, la Sala Constitucional de su Corte Suprema la ha descalificado porque declara nulos los nombramientos estatales de quienes la emprendieron habida cuenta de que su condición personal no era civil sino sólo militar, es decir, que en nombre del Estado no tenían la autoridad constitucional de éste para firmar la tregua porque por parte del Estado la llevaron a cabo dos militares, de rango General, David Munguía Payés y Francisco Salinas, el primero nombrado como Ministro de Seguridad y el segundo como director de la Policía Nacional Civil ${ }^{13}$.

\footnotetext{
12 Los templarios se llevaban a las mujeres y no las devolvían hasta que estaban embarazadas. El hecho no deja de ser histórico. Desde que en 1911 -al comienzo de la Revolución- Emiliano Zapata y Francisco Villa avanzaran entregando tierras a los desharrapados, por primera vez un grupo armado como el de estas autodefensas devolvió a sus propietarios las hectáreas de terreno recuperadas a tiro limpio a los Caballeros Templarios. La Presidenta de Organizaciones Michoacanas Pro Derechos Humanos, Cristina Cortés Carrillo ha advertido que estas autodefensas respecto de "los Caballeros Templarios" se están convirtiendo en una "pre insurgencia" y añadió que había enviado una solicitud formal al Alto Comisionado de Naciones Unidas en México (ONU) para informarle de la gravedad de la situación, situación cuya violencia se ha cobrado ya más de ochenta mil muertos y ha causado otros treinta mil desparecidos en todo el país. Vid. El País de 14.01.14, Sección internacional, p. 8.: "El conflicto avanza en Michoacán". También para mayores detalles puede verse el dominical de El País de 10.01.14, reportaje: "Los justicieros de Tierra caliente".

${ }^{13}$ La retirada de ambos militares del Gobierno Salvadoreño no sólo podría poner en peligro el mismo acuerdo en ese país sino también en Honduras, lo que supondría un descorazonador fracaso de la tregua que se intenta máxime cuando, comparativamente hablando, Honduras tiene un papel más importante que El Salvador en el tráfico de drogas; tan es así que lo vuelve más susceptible a la violencia asociada
} 
En suma: frente a ese terrorismo "de arriba", pues, el más conocido es el terrorismo "de abajo", es decir, el que responde al pronóstico de la clandestinidad del débil (en el sentido de que quien lo protagoniza es porque si emprendiera una guerra se sabe derrotado de antemano).

No obstante, el modelo criminal mafioso no dejaría de ser, a nuestro juicio, una forma más de terrorismo de Estado porque, además de haberse ya tratado como un paradigma de las relaciones entre política y crimen (Magnus, 1996), puede servir para entender mejor regímenes políticos caracterizados por la violencia más extrema, de los que el siglo XX ofrece un amplio abanico de ejemplos como los que antes ya hemos dado cuenta.

Es más, en Democracia hay también situaciones que pueden entenderse y describirse utilizando determinadas analogías con el modelo criminal mafioso. Es lo que algunos, poniendo como mejor ejemplo el peronismo, llaman mafiosidad democrática:

"El modelo «de influencia mafiosa» en sistemas en los que -cualesquiera que sean sus intenciones últimas- los políticos se someten al juicio electoral, deben soportar, al menos, cierto grado de libertad de expresión y deben aceptar que puede existir algún control por parte de un poder judicial más o menos independiente.

(...) La característica crucial de los servicios que vende la mafia es que, a diferencia de lo que hace -o se supone que hace, o intenta hacer- un Estado respetable, en el que impera una ley igual para todos y se protegen por igual todos los derechos legítimos, la protección mafiosa proporciona ámbitos de impunidad, desigualdad y privilegio para los clientes, amigos y cómplices a expensas de los demás. (...) Otra característica es la siguiente: los políticos actúan con autonomía respecto a sus mandatarios (...) sin respeto hacia las instituciones, ni lealtad hacia su papel y funciones, tratando de obtener de ellas el máximo beneficio partidista posible.

La mafiosidad en democracia puede entenderse como lo contrario del fair play democrático. (...) El político que actúa mafiosamente apura (...) la letra de la ley; interpreta el mandato de sus electores despreciando el que han recibido los adversarios (...) y no sólo no tiene en cuenta la posibilidad de ser desalojado del poder, sino que hace todo lo que está en su mano para dificultarlo" (Linde 2006: $6^{\circ}$ y $8^{\circ}$ párr.)

\section{El caso de la mafia italiana}

Todo lo que se sabe de la Mafia, al estar regida por uno de sus principios básicos, el de "la omertà" o Ley del silencio, según la cual no se habla nada y no se revela nada sino que solo se hace lo ordenado, se debe al juez Giovanni Falcone, Director General del Ministerio de Justicia de Italia, muerto en atentado el 23.05.1992.

al crimen organizado y que, al igual que pasó con El Salvador, es necesario asegurar que la tregua esté realmente respaldada por una política social sólida y comprometida con un fuerte acento en la creación de empleos, es decir, en una labor en la que el Gobierno no puede estar solo (ya que necesita para ello alianzas con el sector privado y otros actores de la sociedad civil).

Puede verse, por ejemplo, El País del domingo 2 de junio de 2013, p. 7, en la Sección de Internacional, donde la información al respecto se recoge bajo el título de "Los mareros se cansan de la guerra". Vid. Asimismo El Mundo del 25 de Abril del 2013, p. 58, Madrid, y El País del mismo día, p. 4, también de la sección Madrid.

Esta banda en España ha sido descabezada en Madrid por la Guardia Civil el mes de abril del 2013 tras varios meses de investigación dimanante de "la Operación Dorado". Esta operación fue el producto de una denuncia, y pasaron de inmediato a disposición judicial (Juzgado de Instrucción $n^{\circ} 3$ de Fuenlabrada) tras los arrestos practicados. La mayoría de ellos recayó sobre personas de nacionalidad ecuatoriana y por cargos tales como los de tráfico de drogas, pertenencia a organización criminal, delito contra el patrimonio, coacciones, amenazas, lesiones, tenencia ilícita de armas y extorsión. 
En la década de los 80 la Casa Nostra siciliana mantuvo una guerra consigo misma. Los Corleonesi, encabezados por Totò Riina, estaban decididos a acabar con los clanes rivales por todos los medios posibles, entre ellos el informante extraditado Tomaso Buscetta, quien prácticamente perdió a toda su familia al ser asesinada por atentados. Gracias a sus declaraciones Giovanni Falcone pudo comprender el complejo y amplio entramado que era la Mafia, una organización que funcionaba como un todo, fuertemente jerarquizada, en la que no se hacía nada sin la orden de sus mandatarios. Esa fue la clave para sentar en el banquillo de los acusados a los grandes capos en el Maxi-proceso de Palermo. El 16.09.1087 se absolvió a 114 de los 474 acusados. A los 360 culpables se les condenó a un total de 2665 años de cárcel (AA.VV., 2012).

Los mafiosos se consideran a sí mismos "hombres de honor". Tienen una deontología ${ }^{14}$ permanente, similar a los mandamientos. Por un lado, les obliga a cumplir con los valores internos de "la famiglia" y a no cuestionarse ninguna orden, incluso la de matar. Por otro lado, esa ética es signo distintivo respecto de otras mafias, caso sobre todo de los cárteles sudamericanos, por dos motivos. Uno porque esa permanencia en su actuar honorífico ayuda a los funcionarios de justicia a predecir sus comportamientos futuros. $Y$ en segundo lugar porque se trata de una organización que, además, nunca se disuelve ni siquiera si es aprehendido el jefe.

En cuanto a su estructura existe un jefe, tratado como "Don". En segundo lugar el "Consiglieri", hombre de confianza del capo. Sigue el "Sotto capo", gerente de la familia que controla toda la parte operativa y es la voz de la calle. En cuarto lugar el "Contabile", bajo cuya responsabilidad están las finanzas. A él le sucede en jerarquía el "Capogerime", que dirige al grupo de "soldados" que hacen el trabajo sucio junto, en su caso, con el "Giovane dónore", esto es, la persona que sin formar parte de la familia aspira a ingresar en el círculo externo haciendo méritos para ello. Las familias así conformadas se adscriben a una representación provincial y regional. En Palermo existe "La Comisión", que toma las grandes decisiones de la Casa Nostra y funciona como un Estado al tomar decisiones. Tiene grupos humanos adscritos a regiones y una suerte de Parlamento. Esta es un razón de más para defender que la Mafia es incluible en la tipología del terrorismo de Estado aunque, de hecho, no desee disolverlo sino competir con él o, incluso, aliarse con él para debilitar a las instituciones públicas aprovechando sus estructuras formales de poder. Es más, se considera a veces a sí misma como una alternativa al sistema democrático. Al igual que las organizaciones de narcotráfico en Centroamérica llega a donde el Estado no está presente. Reparte la riqueza y es apadrinada por los pobres cuando los mafiosos les dan de comer.

En este sentido ya a fines de siglo pasado se ha llegado a concluir por algunos analistas, de acuerdo con una traducción propia y no oficial, que "en un mundo donde el paro laboral es omnipresente y el empleo precario, donde hay desafección política, y un incremento migratorio que se corresponde con el aumento de la demanda en bienes y servicios ilegales, resulta inevitable que en un futuro habrá una mayor criminalidad de cuello blanco. Frente a ello necesitamos salvaguardar no solo los derechos protegidos por la Convención Europea de los Derechos Humanos sino también todos los derechos sociales, políticos y económicos del ciudadano. Solo mediante una adecuada redistribución de oportunidades y un salubre camino

\footnotetext{
14 "[...] no desear a la mujer de otro hombre de honor; no robar; no explotar la prostitución; no matar a otros hombres de honor salvo en caso de absoluta necesidad; evitar la delación a la policía; no enfrentarse a otros hombres de honor; mostrar siempre un comportamiento serio y correcto; no hablar jamás con extraños acerca de la Cosa Nostra, y no presentarse por iniciativa propia a otros hombres de honor, pues las reglas imponen que otro hombre de honor, conocido de ambos, debe garantizar su respectiva pertenencia a la Cosa Nostra [...]" (Falcone, 2006: 94).
} 
democrático por el que se haga a los políticos responsables de sus actos será posible reducir los daños económicos y, consecuentemente, la violencia que les suele acompañar" (Cesoni, 1999: 168-169).

Otra razón adicional para incluirla en la tipología predicha, tal como hacemos, es que se parece con el Estado en que ambos utilizan la fuerza solo como último recurso y con intención ejemplarizante porque la regla es la mayor efectividad sin el menor riesgo. No obstante, la forma de hacerlo es no dejando ninguna evidencia: se procede al estrangulamiento de la víctima y se disuelve el cadáver en ácido para que nadie lo encuentre ("Iupara bianca" [Dáll'Anese, 2012: 12]). Si al momento de investigar un homicidio la policía descubre un cuerpo britalmente castigado con anterioridad a la muerte, es indicio de que la víctima fue miembro de la Mafia.

\subsection{Origen geográfico}

Una precaución metodológica que se suele advertir en torno a la naturaleza de la Mafia es que se trata de un "fenómeno multidimensional" (Sciarrone, 2009: XXXIV266) que no admite una explicación unívoca de su existencia. En caso contrario se correría el riesgo de formular un "esquema único, válido para todas las situaciones y todos los tiempos" (Lupo, 1996: 26).

La Mafia se trata de un fenómeno que tiene un origen italiano. Una explicación de sus orígenes remotos, una leyenda negra, se remonta al siglo XVIII a partir de los sentimientos desconfiados y de temor generados en la sociedad siciliana por la dominación española de la Casa de los Austria. Sin embargo, esa teoría se ha revitalizado al considerar que la mafia siciliana sería una especie de defensa natural generada por una sociedad en la que a raíz del modelo de ese dominio español "nadie confía en nadie" y, desde luego, nadie confía en la autoridad o el Estado (Pagden, 1988). De hecho, para el único jefe mafioso que ha contado su vida, Joseph Bonanno, perteneciente a la Casa Nostra, la mafia siciliana sería «un sistema subcultural», "un estilo de vida para sobrevivir", surgido de la larga historia de opresión extranjera sobre la isla, una defensa "natural» de sus habitantes frente a poderes siempre lejanos, explotadores, ineptos e injustos (Bonnano, 2003: 30, 39-40 y 52). ${ }^{15}$

Pero en cuanto a sus orígenes modernos sí es pacífico por parte de los historiadores y economistas que la mafia siciliana surgió a mediados del siglo XIX con más fuerza en Palermo que en Mesina (Gaambetta, 1996: 75).

Una línea de investigación de sus orígenes, continuista con la anteriormente expuesta, mantiene que las primeras agrupaciones mafiosas "se forman sobre el modelo de las sectas secretas anti-borbónicas y masonería en la época de incubación del movimiento nacional (Dovizio, 2005: 97). A partir de asociaciones de este tipo se tomó prestado el variado patrimonio organizativo, ritual y simbólico que desde entonces será característico del universo mafioso, manteniéndose incluso a veces inalterado hasta nuestros días. Teniendo en cuenta las diferencias sustanciales entre sus respectivos ámbitos de origen y desarrollo, "parecen haber sido vectores comunes de irradiación de estos fenómenos las cárceles y el ejército" (Sales, 2014). Es decir, son lugares típicos donde podía haber circuitos de conspiración. De hecho, sus formas de delincuencia asociada imitaron la forma de actuar de las sociedades secretas de la burguesía y de la aristocracia, nexos con los que parece entroncarse

\footnotetext{
15 La primera edición de este libro apareció en 1983. En su «explicación» los mafiosos, «hombres de honor», son los verdaderos héroes del pueblo siciliano, los que ayudaban a los humildes frente a la crueldad e injusticia de los poderes oficiales, los que ayudaron a Garibaldi a derrocar a los Borbones españoles e incluso, un siglo después, a derrocar al fascismo ayudando a la liberación de la isla por las fuerzas norteamericanas.
} 
el carácter elitista y de representación de los débiles por los grupos mafiosos hasta erigirse en guardianes de los valores tradicionales como el honor y la obediencia (Lupo, 2007: 101-107).

Otra línea de investigación, no incompatible con la anterior, explica que la Mafia surgió con más fuerza en Palermo que en Mesina debido al gran aumento de propietarios como consecuencia de los procesos de desamortización y la fragmentación de los latifundios y de las tierras comunales a partir de la abolición de los derechos feudales con la Constitución liberal de 1820 y en un contexto de agudización de bandidaje favorecido por la casi falta de Estado y debilidad de sus fuerzas del orden. A principios del siglo XX los grandes aparceros, los "gabelloti", se convirtieron así en una "industria" autónoma influyente en la vida política siciliana de Palermo utilizando el crimen sin escrúpulos y como método habitual. Por tanto, la mafia es específicamente siciliana, los fenómenos mafiosos posteriores que se dan en otros lugares, incluso en la propia Italia, no son iguales.

Su expansión a otros territorios obedece a la gran revolución criminal en los veinte años que van desde 1970 a 1990, sobre todo por parte de la mafia siciliana por estar caracterizada desde el principio por una fuerte vocación internacional.

Es la época en que su violencia se hace más intensa. Asume tonos subversivos. Salen a la luz los acuerdos que la unen con el poder político y económico. Es la etapa en que Italia pasa por el terrorismo político de las Brigadas Rojas. Es la época en que la Mafia da el salto cualitativo de la ampliación de su capital proveniente de los tráficos ilícitos de las armas y de la droga.

Es cierto, pues, que cada vez está ya más internacionalizada. También se habla de "mafia china", "la rusa", etc. A título de ejemplo su internacionalidad se demuestra en España con las detenciones de miembros de la camorra, así el clan de "Ios Polverino" ${ }^{16}$. En el caso del modelo mafioso norteamericano de La Cosa Nostra, por su parte, ya se dio un salto decisivo de la lucha contra el mismo cuando en 1970 se aprobó el «Racketeer Influenced and Corrupt Organizations Act» (conocida por su sigla RICO), diseñada expresamente para poder perseguir a los mafiosos en sus negocios legales y sindicales porque, si bien el FBI señala, en particular, la recogida de basuras, el suministro de hormigón y el transporte de artículos de confección y ropa como sectores de tradicional y comprobado control mafioso, si se tuviera que elegir los negocios que no se han dado, o se han dado mucho menos, en otros modelos criminales y que, sin embargo, han sido fundamentales en la historia de la Cosa Nostra, se citan los préstamos clandestinos, los juegos y apuestas ilegales y, sobre todo, el negocio laboral-sindical.

Asimismo, en Egipto conviven poblaciones musulmanas y cristianas coptas. Éstas pagan regularmente protección a capos u organizaciones islámicas para ser protegidos. En Siria y Líbano, por su parte, el sistema del Zaim (capo o cacique) organiza la vida política sobre bases institucionales equivalentes a familias mafiosas y sirven para regular el tráfico de influencias que afectan a la distorsión de las leyes del mercado.

\footnotetext{
16 Vid. El Mundo de 06 de junio del 2013, p. 18: "Los Polverino, un clan muy solvente". La trama tenía tres células encargadas de invertir en bienes inmuebles a lo largo de la costa mediterránea. Llevaba actuando en España desde 2006, cuando su gran capo, Giusseppe Polverino Barone se instaló en Tarragona.
} 


\subsection{Concepto y diferencia con el terrorismo}

Debe ser considerada como una criminalidad organizada que busca infiltrarse cada vez más en los ganglios de la economía, del poder, de la Administración, de las profesiones, del sistema financiero y productivo.

Lo hace a través de acuerdos subterráneos y se infiltra en los negocios que constituyen su verdadero poder, toda vez que no hay que olvidar aquí un dato, estrictamente hablando y para diferenciarlo del terrorismo, pero a veces conectado con él, y es que la Mafia tiene como principal fin el beneficio lucrativo.

En este sentido, tal como propone ${ }^{17}$ el presidente del Senado italiano y ex fiscal nacional de la mafia, Pietro Grasso, puede que la solución venga por golpearla en el bolsillo. Comoquiera que ese beneficio lo pretende alcanzar de cualquier modo también interfiere -si es preciso- en el ánimo de la política en general y del poder en particular. Lo hace creando una competencia desleal y distorsionando el mercado con afán de monopolizarlo. Se trata hoy por hoy de un fenómeno nacional e internacional que no tiene ideología sino que busca una relación con el poder.

Tradicionalmente la Mafia siciliana se había mostrado muy reacia a matar a personajes públicos. Prefería infiltrarse en las estructuras del Estado, no atacarlo. En esos "años de plomo" la anterior confrontación política entre demócratas cristianos y el partido comunista italiano terminó con un "compromiso histórico" que auspiciaba una colaboración de la democracia cristiana de Aldo Moro con el partido socialista, logro que parcialmente se consiguió gracias al apoyo externo del partido comunista italiano al gobierno democristiano de Giulio Andreotti ${ }^{18}$ y que acabó con el asesinato de Aldo Moro. $Y$ es que en los albores de los ochenta, enriquecida por la droga y furiosa por la mínima resistencia del Estado, la organización empezó a matar.

Con la adopción de esas tácticas terroristas, "la Cosa Nostra" terminaría por perder a la mayoría de sus valiosos protectores políticos y por quedarse al descubierto ante los ataques de una magistratura revivida. De hecho, la segunda acusación contra Andreotti tiene que ver con el asesinato, en 1979, del periodista Mino Pecorelli, que llevaba tiempo publicando inquietantes informaciones sobre la financiación oculta de la democracia cristiana. Absuelto en primera instancia, condenado en apelación, el

\footnotetext{
17 Véase su entrevista por El País del domingo 16 de Junio del 2003, p.12, Sección Internacional. Además vid. Montaño (2005) y Caselli (2005).

18 Aunque su actividad pública arrancó a mediados de los cuarenta, podemos resumir su biografía diciendo que en la década de 1960 Andreotti fue designado Ministro de Defensa por Antonio Segni. En este período se dio el escándalo de los expedientes del Servicio de Inteligencia y del Piano Solo, un golpe de estado planeado por el neo-fascista en general Giovanni De Lorenzo. A Andreotti se le encomendó la destrucción de los expedientes. Se ha comprobado que los expedientes, antes de ser destruidos, fueron copiados y entregados a Licio Gelli, líder de la logia masónica secreta. En 1968 Andreotti fue nombrado representante del grupo parlamentario de la Democracia Cristiana, cargo que ocupó hasta 1972. En este año inició su mandato como primer ministro de Italia. Ocupó el cargo en dos períodos consecutivos de centro-derecha (1972-1973). Accedió al cargo con apoyo del Partido Liberal Italiano y el Partido Republicano Italiano. Abandonó el cargo en 1973 para volver en 1976 después de las elecciones generales. Duraría en el cargo tres años más, hasta 1979, sostenido su gobierno por el Partido Comunista Italiano, sin que hubiera ministros comunistas, gracias al llamado Compromesso storico. No volvería a ocupar el puesto de presidente del Consejo de Ministros hasta 1989, con la coalición del Pentapartito. Sus tres años como primer ministro coincidieron con el destape de los casos de corrupción que acabarían con el sistema político. Desde 1991 fue senador vitalicio en el Senado de Italia. Tras las elecciones generales de 2006 fue propuesto por el centro-derecha (la Casa de las Libertades) para presidir el senado. Sin embargo, perdió la votación ante Franco Marini. Poco después, los senadores vitalicios acordaron mantener al gobierno de Romano Prodi, lo que provocó la ira de muchos políticos de la Casa de las Libertades hacia Andreotti, al considerar su apoyo a Prodi como una traición, aunque él no perteneciese a ningún partido. Andreotti murió el 6 de mayo de 2013 a la edad de 94 años en su casa de Roma (Italia), a causa de una crisis respiratoria.
} 
Tribunal Supremo italiano confirmó el primer juicio por falta de pruebas. Lo único por lo que Andreotti fue condenado fue por difamar a un magistrado.

\subsection{Su giro terrorista: el caso Andreotti}

El caso Andreotti es el mejor exponente de esas consecuencias políticas del giro terrorista que dio la Mafia en los años ochenta.

En 1989 el mayor enemigo de "la Cosa Nostra", el heroico juez Giovanni Falcone, llegó al Ministerio de Justicia, en el que creó los organismos de investigación que todavía hoy dirigen la lucha contra el crimen organizado en Italia.

En 1992, "la Cosa Nostra" reaccionó ante esa amenaza. Salvo Lima, el lugarteniente de Andreotti en Sicilia, murió tiroteado en Palermo.

Por tanto, cuando se habla sobre la relación entre la Mafia y la política en la historia de Italia la Mafia no sólo no ha sido anatema para las instituciones del Estado, sino, en muchas ocasiones, un grupo de presión más con el que había que contar. Andreotti no fue condenado por los plazos de prescripción de los delitos y su ruptura en 1980 hizo que tuviera efecto esa prescripción, de forma que los Tribunales le consideraron culpable, pero no pudieron castigarle.

Sin embargo, fallecido a primeros de Mayo del 2013 fue lo suficientemente hábil como para llevarse a la tumba tal vez demasiados secretos, siendo el más morboso de todos sus explicaciones sobre el secuestro y posterior asesinato de Aldo Moro. Fue Andreotti -como jefe de Gobierno y recientemente elegido como primer ministro- quien se negó a negociar con los terroristas, cosa que la familia Moro nunca le perdonó, si bien este hecho de anteponer firmemente "la razón de Estado" a la salvación de Aldo Moro, acabaría a la larga por desembocar en la desaparición del grupo asesino de las Brigadas Rojas. En suma, en los llamados años de plomo fue el hombre clave. Después de que en 1987, y coincidiendo con los procesos de corrupción de Tangentópolis, tuviera lugar un macro proceso por el que se condenara a trescientos sesenta mafiosos, "la Cosa Nostra" echó un pulso al Estado para obligarle a negociar con ellos. Comenzaron asesinando al europarlamentario Salvo Lima, y siguieron con otros muchos atentados.

\subsection{Organizaciones mafiosas italianas}

La Cosa Nostra no es un asunto del pasado. El último jefe de jefes, Salvatore Totò Riina, detenido en 1993 y condenado a 13 cadenas perpetuas por el asesinato de 150 personas -a 40 de ellas personalmente-, ha amenazado de muerte a Nino Di Matteo, uno de los fiscales de Palermo que investiga el supuesto pacto entre el Estado y la Mafia para acabar con la matanza de los años noventa.

El Fiscal Franco Roberti, fiscal jefe de la Dirección Nacional Antimafia, ha llegado a advertir ${ }^{19}$ que las cuatro mafias italianas -entre las más peligrosas de las 3.700 que según Europol actúan en Europa- se están haciendo más fuertes gracias a la crisis económica. Según él "cuando la mafia no dispara, hace negocios, no es que no exista", y este es el momento, por ejemplo, en el que la Costra Nostra siciliana,

\footnotetext{
${ }^{19}$ El País de 15.12.2003, Sección Internacional, p. 9, con la noticia titulada "Existe un gran riesgo de que Casa Nostra vuelva a los atentados".
} 
después de un período de gran dificultad, está intentado levantar un poco la cabeza y retomar el fenómeno de la extorsión y de las amenazas.

Según él, la'Ndrangheta calabresa es sin duda en estos momentos la más peligrosa del mundo por su capacidad de traficar con drogas a nivel mundial y también de infiltrarse profundamente en el tejido económico, social y político no sólo de Calabria.

Luego está la Camorra napolitana, que también tiene capacidad expansiva extra regional, si bien todos los capos de la Camorra menos uno, aunque más que un capo es el hijo de un capo, están ahora mismo detenidos y bajo el régimen expresamente previsto para los jefes mafiosos de cárcel dura e incomunicada del art.41 bis del Código Penal italiano.

Por cuanto se refiere a la criminalidad de la Apulia -la Sacra Corona Unita- ha sido golpeada con fuerza, también desde la fiscalía de Roma. La crisis económica y la consiguiente dificultad de acceder al crédito bancario por parte de los empresarios ofrece una oportunidad a las organizaciones mafiosas de blanquear los capitales mafiosos, lo que es de una gravedad extrema en el sentido de que el mafioso financia al empresario con capital ilícito y mete en empresas sanas el capital mafioso. Es un peligro porque además las mafias se aprovechan del desempleo, sobre todo reclutando desesperados sin trabajo para sus propias filas. Las mafias siempre se aprovechan de la desigualdad para hacer negocios más potentes, sin escrúpulos, y para reclutar desesperados. Otro riesgo es el del abandono escolar por cuanto que los chavales sin escolarizar se exponen a ser reclutados por las organizaciones criminales.

Por último, en cuanto al perfil del mafioso, si se busca su figura tradicional, aquel con la Coppola storta (boina torcida), el paleto, ignorante, analfabeto y sanguinario, se encuentra muy raramente, o quizá ya no se le encuentra, también porque los viejos capos están muertos. Ahora el mafioso es sustancialmente un ejecutivo que difícilmente se reconoce a primera vista como mafioso. Se trata de verdaderos mafiosos, pero mimetizados, porque una de las prerrogativas de la mafia es la de confundirse con la sociedad civil. Se les encuentra en las profesiones, en política, en las instituciones. Así que es difícil reconocerlos. Se les descubre solo a través de investigaciones profundas. Por tanto, la armonización de las leyes es el arma más eficaz contra las mafias así como una cooperación eficaz de policía y de órganos jurídicos. Hay que prever la incriminación de testaferros, como se hace en Italia desde hace 20 años, y después prever la confiscación de los capitales a los mafiosos que no consigan demostrar su procedencia.

\subsection{Juicio del siglo}

En la actualidad se ha juzgado tal pulso. Se llevó a cabo en Palermo el llamado "juicio del siglo", proceso que si bien arrancó el día 27 de Mayo del 2013 ha exigido años de investigaciones y lo insólito del mismo no es sólo que el Estado italiano juzgue al propio Estado italiano, sino que en el banquillo de los acusados hay importantes representantes de la Administración italiana junto a quienes deberían ser sus enemigos: los $\operatorname{capos}^{20}$ de "la Cosa Nostra".

Lo que se juzga es que, tras la campaña de violencia mafiosa de los 90 , el Estado italiano hubiera negociado un acuerdo con "la Cosa Nostra" por suavizar las

\footnotetext{
${ }^{20}$ Su gran capo, el feroz Toto Riina, o Leoluca Bagarella, Antonio Cina Giovanni Brusca y Massimo Ciancimino.
} 
condiciones carcelarias de los mafiosos a cambio de que pusieran fin a sus sangrientos ataques, de forma que entre los representantes del Estado imputados por ello estarían Nicola Mancino (Ex Ministro del Interior), un senador (Marcello Dell'Utri) y tres representantes del cuerpo especial de los carabinieri, todos ellos ocupando cargos en un contexto donde, por ejemplo, el juez antimafia de 1992, Paolo Borsellino, pudiera haber sido abatido por constituir un obstáculo en las negociaciones entre el Estado italiano y la mafia según dos ${ }^{21}$ ex mafiosos reconvertidos en colaboradores de la justicia. Los procesos sobre la mafia son lentos y en Italia juzgar este fenómeno ha supuesto una revolución en el sistema de ataque a la criminalidad organizada en cuanto que está conectada con otras realidades sociales, económicas, políticas y de otro tipo, de tal suerte que si se examina el fenómeno criminal de forma aislada es difícil que la Mafia se pueda llegar a comprender como tal fenómeno no exclusivamente italiano.

La Sentencia de abril de 2018 ha condenado al jefe corleonés Leoluca Bagarella, al médico de confianza de Totò Riina, Antonino Cina, a los oficiales del ROS Antonio Subranni, Mario Mori y Giuseppe de Donno, y al ex senador de Forza Italia, Marcello Dell'Utri por atacar al cuerpo político del Estado. En su valoración el Fiscal Nacional Antimafia, Di Matteo, mantuvo públicamente que "Es un momento importante para entender que la lucha contra la mafia si bien debe llevarse adelante con la represión del ala militar o brazo armado de Cosa Nostra, también debe ocuparse de cortar de una vez por todas las relaciones que la mafia siempre mantuvo con los políticos y las instituciones. Esta es una conclusión positiva para creer que el Estado puede comprometerse y es capaz de hacer esto". Di Matteo, mientras recordaba los ataques y obstáculos sufridos en los años en que tramitó el proceso ("en estos años, no todos se han mostrado respetuosos de un trabajo que nos costó lágrimas y sangre") hizo hincapié también en que "no tiene importancia quienes fueron los que nos atacaron, lo importante es que una Corte d'Assise, después de cinco años de proceso, ha reconocido que una parte del Estado negociaba con Cosa Nostra en la época de las masacres y llevaba al gobierno del Estado las exigencias de Cosa Nostra. Este es un fallo que por primera vez consagra, a un nivel tan alto, cuáles fueron las relaciones externas de Cosa Nostra con las instituciones en el momento de las matanzas y es muy significativo que la sentencia de hoy, y probablemente también los considerandos de la Corte lo hayan señalado, haya cubierto un período en que hubo tres gobiernos diferentes, puesto que algunos de los acusados fueron condenados por crímenes cometidos mientras estaban en el cargo los gobiernos de Andreotti y el gobierno de Ciampi, y otros fueron condenados (Dell'Utri, ndr) por haber actuado como intermediarios entre Cosa Nostra y Berlusconi incluso después de $1992 " 22$.

\subsection{Su perversidad y remedio}

Debe de pensarse que más de cincuenta Estados en el mundo, según estudios ${ }^{23}$ de la CIA, están influidos por sus mafias criminales, sobre todo por las que se dedican al tráfico de estupefacientes, que disponen de un poder económico notable para

${ }^{21}$ Gaspare Spatuzza y Giovanni Brusca. Véase el periódico El Mundo del 28 de Mayo del 2013, p.13, sección Mundo, sobre el histórico macro proceso y escándalo político con la información subtitulada "El Estado italiano en el banquillo de los acusados", así como el reportaje de Domingo del periódico El País, de 2 de Junio de 2013, "Cuando el Estado se vendió a la mafia", donde con la foto del cadáver de Salvo Lima en la calle y con el título de "El pacto que apaciguó al diablo" relata los cargos y detalles de todos los acusados del Estado y de la Mafia para afirmar que, al contrario que en "la Cosa Nostra", donde hay decenas de arrepentidos, aún no hay ningún arrepentido entre las filas del Estado. Ningún político, militar o policía de la época ha decidido romper el pacto de silencio y contar la verdad de la negociación.

22 Vid. artículo publicado en Archivo temático, mafia italiana, de la revista electrónica "Portada" de Uruguay: "Sentencia histórica que demuestra que el proceso debía hacerse", de 28.04.2018.

${ }^{23}$ Vid. El País del 16 de Junio del 2003, Sección Internacional, p. 12. 
comprar voluntades y, por tanto, según se define la perversidad, perturbando el orden o estado de las cosas, en este caso decisiones personales, de forma maliciosa.

Dada la preocupación de la Comunidad Internacional, la Convención de las Naciones contra la Delincuencia Organizada Transnacional, firmada en Palermo en el año 2000 y con entrada en vigor el 29.09.2003, ha sido la primera respuesta global a esa amenaza con el fin de promover la cooperación multilateral y prevenir y combatir eficazmente la delincuencia internacional. Por ella los Estados asumen identificar los procesos de globalización, capitalizados por las redes de la delincuencia internacional como espacios propios para refugiarse de la acción de las autoridades y de atacar de manera frontal la delincuencia internacional y sus manifestaciones. Ninguna jurisdicción puede poner fin por sí sola al poder económico y corruptor de las redes delictivas transnacionales.

Una herramienta de consuno, fundamental para el sistema judicial y cooperativo internacional desde entonces, son los Compendios de casos de delincuencia organizada. Evalúan amenazas, sus tendencias, y ofrecen buenas prácticas a raíz de la exposición casuística.

El que ha sido confeccionado por la Oficina de las Naciones Unidas contra la Droga y el Delito en el año 2012, en cooperación con el Gobierno de Colombia, Italia y la INTERPOL, dividido en seis Capítulos, abarca más de 200 casos $^{24}$ y ejemplos de leyes nacionales, habiendo sido expertos españoles para su labor, según su Anexo III, los titulares entonces de la Dirección Antidroga de la Oficina de la Fiscalía General, de la Coordinación de Inmigración de la Oficina del Fiscal, y el del Centro de inteligencia contra el Crimen organizado de la oficina del Fiscal General.

En materia sustantiva (Capítulo I) estudia el alcance de aplicación de la ley penal nacional contra la delincuencia organizada, el delito de participación en un grupo organizado, la responsabilidad de personas jurídicas y la extensión de las jurisdicciones penales nacionales. El Capítulo II aborda desde una perspectiva preventiva, proactiva y holística la parte procesal de investigación y enjuiciamiento sin restar importancia a la labor de inteligencia para lograr el desmantelamiento de los grupos. El Capítulo III aborda la cooperación internacional y el IV el decomiso. EI Capítulo $\mathrm{V}$ trata de delitos específicos (armas de fuego, blanqueo de dinero, piratería marítima, delitos contra bienes culturales y medioambientales) y, por último, el Capítulo VI todo lo relativo a la prevención en materia de delincuencia organizada.

\section{Conclusiones}

El terrorismo de Estado, para diferenciarlo del terrorismo "de abajo" o subversivo, se le conoce también como terrorismo "de arriba". Respecto al terrorismo de abajo, a diferencia de Llobet Anglí, pensamos que puede atacar también a una organización no democrática, incluso a la ONU o a un Estado no democrático, y por tanto ser ese acto encuadrable como terrorismo propiamente dicho y no necesariamente como un crimen de lesa humanidad. Habrá que estar a la casuística para las calificaciones jurídicas.

\footnotetext{
${ }^{24}$ En el listado del Anexo II figuran presentados por España (1) como delito de tráfico de drogas y otros relacionados con drogas los casos SPA 1 (Operación Guadaña, con el delito asociado de participación en un grupo delictivo organizado), SPA 2 (Operación Destello, con el mismo delito asociado que el anterior), y SPA 5 (Operación Chicago, con el mismo delito asociado que antes), (2) como delito ambiental SPA 8 (Operación Rapiña), (3) como delito de contrabando de inmigrantes SPA 3 (Operación Petrolero), y como delito de tráfico de personas SPA 4 (Operación Trufas) y SPA 7 (Operación Clubes), haciéndose referencia al caso SPA 6 solo en el interior y no en el Anexo.
} 
El de Estado desborda el campo propio del Derecho Penal Interno. Es el terrorismo más vil porque elimina todo riesgo y se prevale de la autoridad para perpetrar crímenes. Ni genocidio ni crimen de lesa humanidad son terrorismo propiamente dicho aunque sí se puedan ejecutar con actos no menos graves de terror.

Entre los tipos del terrorismo de Estado están, primero, el de los estados totalitarios, que no sólo dictaduras, en cuya legislación se pretende la aniquilación del enemigo. A nuestro juicio, en función del estudio aquí realizado, incluiríamos el caso de la mafia italiana.

La mafia italiana, como criminalidad organizada y de corrupción que no suele tener ideología, se infiltra en los ganglios del poder estatal. Es la más emblemática, pero no la única. Su peculiaridad nacional es que no sólo ha sido el propio Estado italiano el que se ha juzgado a sí mismo sino que en el banquillo de los acusados ha habido importantes representantes de la Administración italiana junto a los capos que debieran de ser sus enemigos. Tiene como principal diferencia que su principal fin es el beneficio lucrativo. En cuanto al perfil del mafioso tradicional ha cambiado. Hoy por hoy es sustancialmente un ejecutivo. La armonización de las leyes, igual que con el terrorismo, es el arma más eficaz contra ella así como una cooperación eficaz de policía y de órganos jurídicos.

La incluimos en esta tipología de los terrorismo de Estado (depredador, y no contractual) porque (1), según se puede definir, es una forma de poder criminal que reproduce o remeda elementos del poder estatal y trata de recibir compensaciones que pueden considerarse análogas a las que, normalmente, están reservadas al Estado, (2) porque se ha tratado ya como un paradigma de las relaciones entre política y crimen, (3) porque puede servir para entender mejor regímenes políticos extremadamente violentos como los que en el siglo XX se han puesto como ejemplo, (4) porque en Democracia hay sistemas políticos análogos al mafioso ("mafiosidad democrática"), (5) porque se parece con el Estado en que ambos utilizan la fuerza solo como último recurso y de forma ejemplarizante, (6) porque no desea disolverlo sino competir con Él o, incluso, aliarse debilitando las instituciones públicas y presentándose como un sistema alternativo al democrático, y (7) por último, porque en Palermo existe "La Comisión", que toma las grandes decisiones de la Casa Nostra y funciona como un Estado al tomar decisiones. Tiene grupos humanos adscritos a regiones y una suerte de Parlamento.

En segundo lugar, el de las extralimitaciones de los poderes públicos en la lucha contra el terrorismo. Se han puesto como ejemplos el caso de los grupos antiterroristas de liberación (Israel con Septiembre Negro tras los atentados de la olimpiada de Münich y España con los GAL). Como supuestos más modernos hemos referido el caso de Ríos Montt en Guatemala, tan atroz o más que el caso sudafricano del Apartheid, y el caso Faisán en España.

Y en tercer lugar, el de la violencia de grupos paramilitares o por los propios cuerpos de seguridad, pero al margen de la Ley y con impunidad. En este apartado hemos puesto como ejemplo a Hamás en Palestina cuando ganó las elecciones en 2006, el de EE.UU en su apoyo a la contra Nicaragüense, Afganistán a Al Qaeda o Libia en el caso Lockerbie de 1988, entre otros como los más recientes que hemos narrado a través del crimen internacional protagonizado por ciertas bandas latinas y su contestación con grupos de autodefensa.

Para terminar, al haber tratado en este artículo solo de la Mafia italiana y no de otras, sí cabe en todo caso distinguirlas, sobre todo de los cárteles sudamericanos, en que su "permanente actuar honorífico" es un signo distintivo que paradójicamente 
ayuda a los funcionarios de Justicia a predecir sus comportamientos futuros y, en fin, que se trata de una organización que nunca suele disolverse ni siquiera si es aprehendido el capo. La mejor opción de su lucha contra ellas es así desmantelarlas por Derecho de arriba abajo.

Medios hay: aunque ninguna jurisdicción puede poner fin por sí sola al poder económico y corruptor de las redes delictivas transnacionales, uno de ellos, la armonización de las leyes, es el arma más eficaz contra las mafias así como, en segundo lugar, una cooperación eficaz de policía y de órganos jurídicos. Por último, existe una herramienta de consuno, fundamental para el sistema judicial y cooperativo internacional, que son los Compendios de casos de delincuencia organizada. Evalúan amenazas, sus tendencias, y ofrecen buenas prácticas a raíz de la exposición casuística.

\section{Bibliografía}

AA.VV. (2012), Giovanni Falcone. Conferencias magistrales. 21. La lucha contra el Crimen organizado. Tres conferencias, Instituto Nacional de Ciencias Penales, México, $4^{\mathrm{a}}$ ed.

ANONIMO (2005), "El fenómeno pandillero", Revista El Monitor, núm. 11, Boletín de Vigilancia Tecnológica, disponible en la siguiente dirección electrónica: www.uned.es/dpto pen/delincuencia-juv/.../fenomeno pandillero.pdf. (fecha de consulta: 25 de julio de 2018).

ANONIMO (2018), "Sentencia historica que demuestra que el proceso debia hacerse", en Portada, revista electrónica de Uruguay, archivo temático, mafia italiana, de 28.04.2018, disponible en: www.antifiadosmil.com (fecha de consulta: 25 de julio de 2018).

ANONIMO (n.d.), "La guerra de Argelia en el Glosario de la Historia de las Relaciones internacionales durante el siglo XX", Revista Historias siglo20.org, en el apartado de Guerra Fría, disponible en la siguiente dirección electrónica: www.historiasiglo20.org/GLOS/guerraargelia.htm (fecha de consulta: 25 de julio de 2018).

ARANDA, D. (2010), Argentina Originaria: genocidios, saqueos y resistencias, Lavaca, Buenos Aires.

BONNANO, J. (2003), A Man of Honor, St. Martins Paperbacks, Nueva York.

BOTELLO, S. y MOYA Á. (eds.) (2005), Reyes latinos, Temas de Hoy, Barcelona.

CASELLI, G.C. (2005), "Los instrumentos internacionales en la lucha contra el crimen organizado", en CÁMARA DE LANDA, E. y MORABITO, S. (coord.), Mafia, Ndrangheta, camorra: en los entresijos del poder paralelo, Secretariado de publicaciones e Intercambio Editorial, Valladolid.

CERBINO, M. (2004), Pandillas juveniles, cultura y conflicto de la Calle, EI Conejo/Abya yala, Ecuador.

CESONI, M.L. (1999), "Mafia-Type Organizations: The Restoration of Rights as a Preventive Policy", en VIANO E., Global Organized Crime and International Security, Ashgate.

DÁLL'ANESE, F. (2012), Contra la Mafia: lecciones aprendidas, conferencia dictada en el Instituto de Cultura, Guatemala de la Asunción, el 19.07.2012, en conmemoración del XX aniversario del fiscal anti-Mafia italiano Paolo Borsellino.

DOVIZIO, C., (2005), "Historias de la Mafia en Italia. Una hipótesis interpretativa", Tiempo Devorado. Revista de Historia Actual, núm. 1: Estado, Criminalidad y cambio político, entre Italia y Latinoamérica.

FALCONE, G. (2006), Cosas de la Cosa Nostra, Ediciones Baratalia, Barcelona. 
GAMBETTA, D. (1996), The Sicilian Mafia. The Business of Protection, Harvard University Press, Cambridge.

GONZÁLEZ CUSSAC, J.L. (2006), "El Derecho Penal frente al terrorismo. Cuestiones y perspectivas", en GÓMEZ COLOMER, J.L y GONZÁLEZ CUSSAC, J.L (coords.), Terrorismo y proceso penal acusatorio, Tirant lo Blanch, Valencia.

LINDE, L.M. (2006), "Mafia como política, política como mafia", Revista de Libros, segunda época, Sociología, nº 120.

LLOBET ANGLí, M. (2010), Derecho Penal del terrorismo. Límites de su punición en un Estado democrático, La Ley, Madrid.

LUPO S. (2007), Che cos'è la mafia. Sciascia e Andreotti, lántimafia e la política, Donzelli, Roma.

LUPO, S. (1996), Storia della mafia dalle origini ai giorni nostri, Donzelli, Roma.

MAGNUS ENZENSBERGER, H. (1966), Política y delito, Biblioteca Breve, Barcelona.

MONTAÑO, E. (2005), Estrategia de cooperación para contrarrestar la violencia política del terrorismo y del crimen organizado, La Paz, Bolivia.

MOSELLE, B. y POLAK, B. (2001), "A Model of Predatory State", The Journal of Law, Economics, \& Organization, vol. 17, $\mathrm{n}^{\circ} 1$.

PAGDEN, A. (1988), "The Destruction of Trust and its Economic Consequences in the case of Eighteenth Century Naples", en GAMBETTA D. (ed.), Trust: Making and Breaking Cooperative Relations, Department of Sociology, University of Oxford, pp. 127-141.

SALES, I. (2014), "La mafia come método e modelo", Limes. Rivista italiana di geopolítica, $\mathrm{n}^{\circ}$ 11: Quel che resta dell'Italia.

SCIARRONE, R. (2009), Mafie vecchie, mafie nuove. Radicamento ed espansione, Donzelli, Italia. 